\title{
O duplo insight de Fichte
}

Suzanne Dürr

\section{(2) OpenEdition}

Journals

Edição electrónica

URL: https://journals.openedition.org/ref/1892

DOI: $10.4000 /$ ref.1892

ISSN: 2258-014X

\section{Editora}

EuroPhilosophie Editions

Refêrencia eletrónica

Suzanne Dürr, «O duplo insight de Fichte», Revista de Estud(i)os sobre Fichte [Online], 23 | 2021, posto online no dia 01 dezembro 2021, consultado o 05 março 2022. URL: http://journals.openedition.org/ ref/1892 ; DOl: https://doi.org/10.4000/ref.1892

Este documento foi criado de forma automática no dia 5 março 2022

(c) EuroPhilosophie 


\section{O duplo insight de Fichte}

\section{Suzanne Dürr}

\section{NOTA DO EDITOR}

Tradução de Hans-Christian Klotz (UFG). Revisão de Thiago S. Santoro (UFG)

\section{1) 0 insight originário de Fichte: a reflexividade e a circularidade da autoconsciência}

\section{a) As três fórmulas como crítica da teoria da reflexão}

1 No seu artigo programático "O insight originário de Fichte" (1966) Henrich fez uma contribuição central para a iniciação de uma pesquisa sistemática sobre Fichte e, além disso, para a teoria da autoconsciência. Contra a crítica pós-moderna de teorias da subjetividade, Henrich destaca aqui a importância central da teoria fichtiana da autoconsciência ao localizá-la com relação a três épocas: após uma pré-história, que se estende da antiguidade tardia até o início da época moderna e na qual a autoconsciência possui apenas uma importância marginal, de Descartes a Kant ela possui a função de um princípio de fundamentação. No entanto, segundo Henrich, não se investiga nisto "que ela é em si mesma e em como ela pode ser pensada enquanto tal." ${ }^{1}$, isto é, a estrutura interna e a caracterização conceitual da autoconsciência ficam em aberto. É no início da terceira época que Henrich localiza o modelo fichtiano da autoconsciência. Fichte teria realizado uma mudança de paradigma ao colocar as características e a estrutura da autoconsciência como tal no centro da sua investigação. Segundo Henrich, todas as teorias da autoconsciência até Kant operam com o mesmo modelo da estrutura da autoconsciência que pode ser denominado de "teoria da essência do eu como reflexão"2. A teoria da autoconsciência como reflexão pode ser descrita pelas seguintes características: 1) o eu é concebido como um ato que é explicitado através dos componentes sujeito, objeto e a relação entre ambos; 2) a relação entre sujeito e objeto pode ser caracterizada como relação consigo mesmo ou 
reflexão, na qual o sujeito ativo se torna objeto de si mesmo através de um ato livre, reconhecendo a si mesmo nele ao abstrair de todos os objetos particulares; 3) pelo ato de voltar-se para si mesmo é estabelecida uma identidade de sujeito e objeto. Esta pode ser explicitada pela equação "eu = eu".

2 Mesmo que a teoria da reflexão pareça plausível em um primeiro momento, segundo Henrich ela não o é, porque subjaz a ela uma confusão do fenômeno da autoconsciência com a sua descrição. Assim, segundo Henrich, o que é circular é a própria teoria da reflexão, e não o eu como fenômeno a ser descrito. Henrich indica duas dificuldades fundamentais da teoria da reflexão, interpretando o modelo fichtiano como resposta à primeira. A primeira dificuldade pode ser caracterizada como circularidade de espécie ontológica, a segunda como circularidade de espécie epistêmica: 1) o sujeito já precisa ser um eu para referir-se a si mesmo. Portanto, o sujeito da autorreferência precisa já satisfazer toda a fórmula "eu = eu" para que haja uma identidade dos relata; 2) o sujeito enquanto eu precisa já saber que o objeto da equação "eu = eu" é idêntico a ele. No entanto, se o sujeito do ato já sabe de si, ele já está no estado de saber "eu = eu". Desse modo, sob dois aspectos a teoria da reflexão pressupõe a fórmula "eu = eu" que é utilizada para a explicação da autoconsciência na derivação dela. $O$ erro do modelo da teoria da reflexão consiste no fato de que ela interpreta a ipseidade originária do sujeito através do fenômeno secundário da reflexão, enquanto na verdade tal ipseidade deve ser entendida como fundamento da possibilidade da reflexão. ${ }^{3}$

Segundo Henrich, as teses centrais da teoria fichtiana da autoconsciência são expressas em três fórmulas, sendo a respectiva fórmula seguinte uma revisão da fórmula anterior, no sentido de uma autocorreção de Fichte. Henrich localiza a primeira fórmula na Doutrina da Ciência de Fichte de 1794, sendo ela: "o eu põe pura e simplesmente a si mesmo". Segundo Henrich, Fichte foi o primeiro a perceber a circularidade do modelo da reflexão, substituindo o paradigma tradicional por um modelo de produção que se exprime na fórmula da autoposição como "imagem negativa do modelo da reflexão" ${ }^{4}$. Esta pode ser caracterizada como proposta contrária ao modelo da reflexão nos seguintes pontos: 1) o sujeito não antecede à autoconsciência, mas surge ao mesmo tempo com toda a consciência "eu = eu". Desse modo, a autoposição explicitaria "essa imediatez na qual todo o eu emerge de uma só vez"; ${ }^{5}$ 2) a autoconsciência não é explicada por uma autorreferencialidade formal, voltada para trás, mas por um ato real de surgimento. Assim, em vez da mera pressuposição da autoconsciência no modelo da reflexão, o modelo da produção explicita a sua gênese; 3) em vez da identidade dos relata, o modelo da produção distingue entre $o$ ato real da atividade enquanto fundamento do saber e, por outro lado, o seu produto enquanto saber.

No entanto, na medida em que o modelo da autoposição é meramente uma resposta ao problema da circularidade ontológica, segundo Henrich, por um lado é defeituoso sob o aspecto do seu conteúdo, porque sendo apenas um "encontro consigo" imediato, está subdeterminado e não pode explicitar a autorrepresentação conceitualmente mediatizada da autoconsciência. Por outro lado, o modelo da produção seria insuficiente também sob o aspecto formal: Henrich critica que agora "elementos da teoria da reflexão se insinuam em seu contraprojeto"', porque nele a direção da autorreferência no modelo da reflexão ficaria meramente invertida. Porque a fórmula da autoposição não pode explicitar o caráter epistêmico do eu, Fichte ampliaria esta numa autocorreção pela fórmula "o eu põe-se pura e simplesmente como se pondo", que Henrich atribui ao Ensaio de uma nova exposição da Doutrina da Ciência (1797/98) e à 
Doutrina da Ciência nova methodo (1796-99). Pela palavra 'como' exprime-se aqui que o eu sabe de si como eu. Na medida em que a primeira fórmula ainda não podia explicar a diferença entre a natureza orgânica e a consciência ao conceber o eu meramente como atividade que retorna para si mesmo, ela mesma torna-se agora alvo da objeção fichtiana contra a teoria da reflexão, na qual o eu é representado apenas como objeto, pressupondo um sujeito pensante. Enquanto a primeira fórmula não esclareceu o estatuto epistêmico do saber, a segunda fórmula caracteriza o eu como unidade cooriginária de intuição e conceito, o que, segundo Henrich, torna mais forte o caráter imediato envolvido na primeira fórmula, aspecto este que se exprimiria particularmente na noção do eu como "sujeito-objeto". Embora a segunda fórmula explicitaria o eu como um saber fechado em si mesmo, segundo Henrich ela torna necessária uma correção ainda mais forte do que a primeira. Henrich indica dois motivos disto: a) por um lado, o eu enquanto faculdade de produção deveria conhecer como é que a partir dele surge a duplicação do autoconhecimento; b) na medida em que o saber do eu é caracterizado como unidade da intuição e do conceito, levanta-se a questão de se no saber como produto também a produção do saber é conhecido. Os dois pontos apontam para uma tensão, inerente à segunda fórmula, entre a imediatez da produção do eu e o caráter mediador do aspecto conceitual. Segundo Henrich, essa dificuldade só pode ser resolvida se se supõe uma diferença entre o eu ativo enquanto ser-para-si e o seu fundamento que não está presente nele. Henrich defende que a terceira fórmula, da Doutrina da Ciência de 1801, orienta-se por essa ideia, definindo o eu como "uma atividade na qual um olho está inserido". Segundo Henrich, a terceira fórmula deve ser interpretada como proposta contrária à primeira, na medida em que, em vez do pôr ativo do saber de si do eu, é afirmado um estar-inserido passivo do olho na atividade do eu.

\section{b) A importância da terceira fórmula para o modelo da autoconsciência de Henrich}

5 Segundo Henrich, como proposta contrária ao modelo da reflexão, o modelo fichtiano da produção é uma resposta à objeção da circularidade ontológica, enquanto a objeção da circularidade epistêmica que Henrich considera decisiva não estaria em foco para Fichte, fato este no qual consistiria o "limite da contribuição de Fichte para a teoria da autoconsciência". Além disso, com a segunda fórmula, que explica o saber na autoconsciência através da fórmula do 'como', surgiria a problemática de uma explicação circular em Fichte. Embora na perspectiva de Henrich Fichte não tenha feito jus à objeção da circularidade epistêmica, Henrich considera possível formular uma solução com os meios propostos por Fichte. Na medida em que Fichte caracterizaria o eu como imediata relação recíproca de intuição e conceito, sua reflexividade não poderia ser entendida a partir de um dos momentos. Por isso, a terceira fórmula anteporia à atividade que vê uma outra atividade como sua origem. Segundo Henrich, desse modo a autoconsciência só pode ser explicitada pela concepção paradoxal de um saber sem sujeito que, como saber imediato, possibilita o 'como' do conceito de eu e a relação entre intuição e conceito no eu. Assim, "as proposições nas quais Fichte, por fim, fala do eu são somente ainda a expressão paradoxal do reconhecimento de que o eu se furta à construção por conceitos." $"$

6 As reflexões sobre a autoconsciência em "O insight originário de Fichte" servem para Henrich em seguida como ponto de partida de uma proposta própria para uma teoria 
da autoconsciência no seu artigo "Autoconsciência. Introdução crítica para uma teoria" (1970), no qual ele busca esclarecer um tema clássico com os meios da filosofia analítico-empirista. Henrich chega ao seu modelo de autoconsciência como "programa mínimo de uma teoria da consciência" ${ }^{10}$ através de um procedimento ex negativo com relação à teoria da reflexão, tal que suas características plausíveis devem ser mantidas, enquanto a circularidade na interpretação deve ser evitada. Segundo Henrich, a consciência não deve ser entendida nem como autorreferência consciente, nem como identificação consigo, mas ser caracterizada como saber imediato. Como já no artigo sobre Fichte, Henrich distingue dois níveis da consciência: por um lado, uma consciência 'sem eu' que ele caracteriza como dimensão anônima, e por outro lado, o si como princípio ativo e autocontrolador. A ilusão de que a autoconsciência seria um princípio ativo teria sua origem no fato de que o saber imediato enquanto "consciência do si sem si" ${ }^{11}$ seria meramente reproduzido pela consciência explícita do si. Henrich inverte a relação da consciência: o sujeito não tem a consciência, mas a consciência ‘tem' o sujeito.

\section{c) Reflexividade e produtividade}

7 Enquanto Fichte atribui à autoconsciência uma estrutura reflexiva, apesar do seu caráter imediato, Henrich a concebe como saber imediato sem autorreferência em sentido estrito. ${ }^{12}$ Henrich defende tal posição também no texto de palestra "Ipseidade e consciência" que surgiu pouco depois de "Autoconsciência" e que ele publicou primeiro em 2007. Na introdução desse texto, Henrich critica a posição outrora desenvolvida por ele: 1) as explicações da autoconsciência como autoatribuição que não é uma autorreferência efetiva exigem mais explicação e seriam elas mesmas circulares; 2) as explicações seriam formuladas meramente ex negativo e, além disso, seriam vagas; 3 ) a concepção da autoconsciência que foi desenvolvida levaria a uma imagem objetivante da subjetividade que seria artificial e inadequada. Desse modo, Henrich abandonou todas as tentativas desse gênero de explicar a autoconsciência, indicando duas razões principais disto: primeiro, todas as tentativas de derivação da autoatribuição de uma autorreferência no saber seriam necessariamente circulares. Segundo, através de mais investigações, Kant teria se destacado para ele como ponto de orientação de uma teoria da subjetividade, na medida em que ele toma como ponto de partida da sua análise conceitos complexos, mas não mais analisáveis. ${ }^{13}$

8 Assim, com relação à interpretação de Fichte em "O insight originário de Fichte" levanta-se a questão de se também uma outra interpretação da teoria da autoconsciência de Fichte do que a defendida naquele texto de Henrich é possível. Em "Autoconsciência", Henrich distingue duas variantes da teoria da reflexão: "a primeira, a kantiana, entende a reflexão como uma atividade do eu, enquanto a outra a caracteriza meramente como uma autorreferência no saber, sem prometer explicações sobre sua origem." ${ }^{14} \mathrm{Ou}$ a autoconsciência seria então pressuposta na sua explicação, ou ela seria explicitada através de uma identificação posterior. No entanto, na medida em que com relação à autoconsciência não haveria possibilidade de identificação errada, segundo Henrich ela deve ser entendida como familiaridade consigo sem identificação de si e, com isso, sem autorreferência. Ora, aqui levanta-se a questão de se da impossibilidade de identificação errada segue-se necessariamente o abandono da reflexão como autorreferência na explicação da autoconsciência. ${ }^{15}$ Para responder essa pergunta, no que segue serão discutidas duas dificuldades de uma concepção da 
autoconsciência que são centrais para Fichte: a circularidade e o regresso infinito. Para tal, será utilizado o primeiro capítulo do Ensaio de uma nova exposição da Doutrina da Ciência (1798), publicado por Fichte, que corresponde ao $§ 1$ da Doutrina da Ciência nova methodo. Aqui, Fichte formula a objeção da circularidade da seguinte maneira:

Foi afirmado: Teu eu é instituído única e exclusivamente pelo retorno a ti mesmo de teu pensar. Em algum pequeno recanto de tua alma encontra-se uma objeção contra isso - ou: devo pensar, mas, para poder pensar, é preciso que antes eu seja; ou então: devo me pensar, retornar para mim, mas aquilo que deve ser pensado, [...] precisa antes ser, para depois ser pensado ou para que se retorne a ele. (DC $180^{16}=\mathrm{GA} \mathrm{I} / 4$, 273)

Segundo Fichte, se o eu deve ser pensado como produto de um agir autorreferencial que retorna para si mesmo, postula-se tanto o sujeito enquanto aquilo que pensa, quanto o objeto enquanto aquilo que é pensado como "um estar-aí, [...] independente do pensar e do ser-pensado de ti mesmo, e como pressuposto dele" (DC 180 = GA I/4, 273). Apesar de Fichte considerar tal alegação um pensamento necessário que se impõe, sendo ele resultado da estrutura reflexiva do conceito de eu, trata-se de um pensamento contraditório, na medida em que a existência do eu que seria independente do pensamento por sua vez pressupõe um sujeito do pensamento. Assim, é necessário antepor à autoposição elevada para a consciência distinta um outro pôr, sem consciência distinta, como sua condição, que se refere ao primeiro (cf. DC 181 = GA I/4, 274). Já na quarta seção da Segunda Introdução da Doutrina da Ciência (1797) Fichte levantara a pergunta de se o eu não precisa existir para si para que possa retornar para si mesmo e tornar-se fim de um agir. Fichte responde aqui que eu surgiria só através de "um agir voltado para um agir" (GA I/4, 213), apenas para o filósofo o eu já estaria dado como fato. $O$ retornar-para-si-mesmo do eu seria uma mera intuição e, com isso, apenar um ato parcial da autoconsciência. Seria apenas uma autoconsciência possível, porque esta, por um lado, precisa ser representada conceitualmente e, por outro lado, precisa ser determinada pela diferença do não-eu. Também no $\S 5$ do Fundamento de toda Doutrina da Ciência Fichte tinha observado que a mera autoposição não pode explicitar o ser-para-si, assim, o eu deve "pôr-se como posto por si mesmo" no sentido da representação conceitual (DC $147=$ GA I/2, 409) para ter uma consciência de si mesmo. Fichte formula então duas respostas contra a objeção da circularidade do seu modelo da autoconsciência: 1) Não se deve supor um ser-aí do eu que seja independente do pensamento. $\mathrm{O}$ eu não seria uma substância, mas mera atividade: "Para o idealismo, a inteligência é um agir, e absolutamente nada além disso; nem como algo que age ela deve ser chamada, porque por essa expressão aponta-se para algo que subsiste e no qual a atividade inere" (GA I/4, 200). A objeção da circularidade estaria fundada na estrutura reflexiva do próprio pensamento. 2) Com relação à explicação da estrutura reflexiva do eu, não se deve pressupor o eu todo como autoconsciência, mas apenas "uma parte da ação toda da inteligência" (GA I/4, 214).

10 Enquanto Fichte discute a objeção do círculo com relação à estrutura autorreferencial do eu como autoposição, com relação à objeção do regresso infinito o método da reflexão está em foco: "observa teu observar de tua autoposição; observa aquilo que, na investigação levada a efeito acima, tu mesmo fizeste, e como fizeste para observar a ti mesmo. Faze daquilo mesmo, que até agora era o subjetivo, o objeto de uma nova investigação (...)" (DC 181= GA I/4, 274). Num primeiro passo, Fichte estabelece a autoconsciência como condição da consciência de objetos ao caracterizar a consciência de um objeto como consciência do pensar do objeto que, por sua vez, pressupõe a 
autoconsciência como atividade do sujeito. Nisto, partindo da concepção kantiana da apercepção pura como consciência acompanhante, segundo a qual o 'eu penso' deve pode acompanhar todas as minhas representações, ele defende a tese de que a consciência de um objeto sem relação com a autoconsciência seria consciência nenhuma. Em um primeiro momento, Fichte agora tenta explicitar a autoconsciência em analogia com a consciência de objetos. Nessa tentativa surge a seguinte dificuldade: o sujeito enquanto pensante deveria ao mesmo tempo ser objeto de um pensamento de ordem superior, porque sem isso ele não poderia ser caracterizado como consciência. No entanto, como nesse caso ele não estaria consciente de si, seria necessário supor um outro sujeito para o qual ele seria um objeto. Portanto, tal explicação resulta num regresso infinito:

Tu tens consciência de ti mesmo dizes; logo, distingues necessariamente teu eu pensante do eu pensado no pensamento do eu. Mas, para que possas fazê-lo, o pensante nesse pensar tem de ser por sua vez objeto de um pensar superior, para poder ser objeto da consciência; com isso, obténs, ao mesmo tempo, um novo sujeito, que deve novamente ter consciência daquilo que antes era o estarconsciente-de-si. [...] e depois de termos principiado a inferir segundo essa lei, não podes mais indicar-me nenhum lugar onde devêssemos deter-nos; logo, para cada consciência, precisaremos de uma nova consciência, cujo objeto é a primeira, e assim ao infinito; logo, jamais chegaremos a poder admitir uma consciência efetiva. (DC $181=$ GA I $/ 4,275)$

11 O modelo comum da consciência que define a consciência como diferença do sujeito e do objeto e que, segundo Fichte, foi defendido em todas as teorias da autoconsciência até Kant, não pode explicar a autoconsciência. ${ }^{17}$ Da falsidade do modelo que em um primeiro momento parece plausível Fichte infere ex negativo que o modelo oposto é válido: a autoconsciência não pode ser entendida como diferença de sujeito e objeto, mas deve ser concebida como sua unidade absoluta. Nisto, Fichte caracteriza a consciência imediata como uma consciência que não está numa relação externa com seu objeto, como se estivesse "acrescentada a ele posteriormente" (DC $182=$ GA I/4, 276), mas que está numa relação necessária com seu objeto.

Enquanto a circularidade abordada por Fichte pode ser identificada com a objeção da circularidade ontológica apresentada por Henrich, o que está em foco no regresso infinito discutido por Fichte é o problema da representação do saber. Nisto, a circularidade apresentada por Fichte não é uma crítica dos seus antecessores, mas trata de uma objeção possível contra o seu próprio modelo da autoconsciência. Em contraste, o problema do regresso infinito, segundo Fichte, teria aparecido nas teorias anteriores da autoconsciência até Kant. Fichte não critica aqui a circularidade dos modelos, mas a concepção unilateral do eu como sujeito meramente formal que deve tornar-se consciente de si através da auto-objetivação de si mesmo. Segundo Fichte, a autoconsciência deve ser entendida como consciência imediata, ou seja, como unidade de sujeito e objeto. Portanto, o que está em foco na crítica fichtiana não é a estrutura autorreflexiva da autoconsciência, mas uma reflexão unilateralmente objetivante. Desse modo, por um lado, o conceito de reflexão é um conceito norteador da Doutrina da Ciência: Fichte entende a fórmula do 'como' no $\$ 5$ do Fundamento como "princípio de refletir sobre si mesmo" (DC 147 = GA I/2, 407) e a intuição intelectual no $\$ 1$ da Doutrina da Ciência nova methodo como "reflexão pura" (GA IV/3, 350). Por outro lado, com a caracterização do princípio da Doutrina da Ciência como pôr-a-si-mesmo Fichte busca explicitar a estrutura da autorreferência reflexiva. Nisto, a concepção da autoconsciência imediata não significa que não há relação consigo, mas refere-se a uma 
autorreferência interna que está mediatizada consigo mesma. Com isso, o modelo fichtiano não é uma crítica do caráter reflexivo da autoconsciência, mas destaca a ligação entre reflexividade e produtividade na autoconsciência. Assim, a autoconsciência não pode ser entendida apenas como forma ou sujeito, mas deve ser caracterizada como unidade originária de forma e conteúdo por ser, enquanto forma, o seu próprio conteúdo. Contrariamente ao contraste entre os modelos de reflexão e de produção que é defendido por Henrich, o modelo fichtiano da autoconsciência pode ser caracterizado como reflexão produtiva ${ }^{18}: 1$ ) o modelo da reflexão produtiva não opera com uma entidade 'eu' como substância, mas entende a autoconsciência como atividade autorreferencial, não sendo por isso atingido pela crítica de uma circularidade ontológica; 2) a discussão fichtiana do problema do regresso infinito pode ser entendida como esclarecimento da circularidade do saber apresentado por Henrich: o saber de si do eu não surge pela ligação externa dos relata sujeito e objeto, mas a própria relação tem que ser entendida como saber; 3 ) a reflexão produtiva não é uma reflexão formal, como no modelo da reflexão que é criticado por Henrich, mas uma autorreferência dotada de conteúdo na qual a atividade do eu é objeto para si mesma. Desse modo, o regresso infinito criticado por Henrich resulta do dualismo de sujeito e objeto. Em contraste, na reflexão produtiva não há relação externa do conceito com a intuição ou do sujeito com o objeto, por isso ela é imune ao erro pela identificação errada. Nesse contexto, Fichte critica nos modelos anteriores da autoconsciência que estes entendem a autoconsciência meramente em sentido formal e, com isso, de modo unilateralmente teórico, na medida em que a dimensão prático-produtiva da autoconsciência não é contemplada. Por isso, ele caracteriza a autoconsciência como unidade do eu teórico e do eu prático ou de conceito e intuição; 4) como a reflexão formal criticada por Henrich, a reflexão produtiva é uma relação consigo mesmo. No entanto, esta não se refere a um saber já existente, como a reflexão formal enquanto relação simétrica, mas é uma produção de saber.

\section{2) Este eu que significa muito: Generalidade e singularidade da autoconsciência}

\section{a) Generalidade e singularidade}

13 O título do seu livro Dies Ich, das viel besagt (Este eu que significa muito) (2019), que Henrich adotou do manuscrito de Leibniz Discours de Métaphysique (1686), aponta para a complexidade e as muitas facetas do campo de problemas em torno da autoconsciência que não permite uma descrição inequívoca e uma solução simples. Henrich adota aqui uma nova perspectiva com relação ao problema da autoconsciência na medida em que as tentativas de resolver o problema no horizonte do artigo sobre Fichte levaram ele “para construções teóricas no entendimento do fato fundamental 'desse eu' que foram manifestamente artificiais e sem o potencial para uma compreensão segura." ${ }^{19}$ Nisto, ele desenvolve uma concepção da autoconsciência como liberdade finita a partir de Kant, tendo "O insight originário de Fichte" como ponto de partida de "pensamentos posteriores" e de novas reflexões. Na medida em que, segundo Henrich, a formulação do problema do artigo não está resolvida nem acabada, o objetivo do livro seria repensá-la "profundamente". Nisto, seria necessário submeter a um novo questionamento a própria interpretação da obra de Fichte e a argumentação do artigo. $\mathrm{O}$ artigo tinha concluído com uma perspectiva sobre a relação entre egoidade como 
forma fundamental da subjetividade e individualidade, entre generalidade e singularidade como condição fundamental da autoconsciência. Enquanto esse aspecto da teoria fichtiana da autoconsciência não foi contemplado no artigo, no livro atual de Henrich ele torna-se o principal tema. Henrich justifica nisto a perspectiva isolada do artigo: por um lado, a intenção era a de dar um impulso para a decifração da obra de Fichte; por outro lado, pretendia-se restituir ao problema filosófico da autoconsciência o seu peso. Em função dessa questão, o artigo desconsiderou dois pressupostos internos do insight de Fichte: 1) o modelo de sistema projetado por Fichte, cujo princípio é desempenhado pelo eu a partir das características da autorreferencialidade e da autodeterminação; 2) a fundamentação fichtiana de uma filosofia prática a partir da filosofia kantiana da liberdade. Com relação à questão da relação entre o princípio do eu e sujeitos singulares, Henrich distingue duas interpretações do insight de Fichte: 1) "a forma mais intrínseca de um sujeito único que antecede e subjaz a qualquer sujeito" e 2) "a autoconsciência de cada sujeito singular que, sob o aspecto desse núcleo, está de acordo com todos os sujeitos" ${ }^{20}$. Enquanto Henrich no artigo sobre Fichte atribui às etapas de desenvolvimento da Doutrina da Ciência certa consequência lógica, agora ele caracteriza esse desenvolvimento como confuso e a proposta de Fichte como profundamente ambígua. ${ }^{21}$ As versões diferentes da Doutrina da Ciência teriam seu motivo no fato de que Fichte não teria refletido sobre a tensão entre generalidade e singularidade na autoconsciência: 1) além da fundamentação do eu como princípio, há a fundamentação de sujeitos reais como plural; 2) o princípio da certeza do saber na Doutrina da Ciência tardia caracterizaria a forma geral da 'egoidade', no entanto, a concepção da certeza deve seu sentido à relação com sua efetuação pela autoconsciência singular de cada um. 3) No lugar da auto-evidenciação (Selbstvergewissetung) da autoposição na primeira fase da Doutrina da Ciência está até a compreensão da necessidade da auto-abdicação (Selbstpreisgabe) do sujeito singular nas Doutrinas da Ciência tardias. ${ }^{22}$ Para Henrich, o insight de Fichte agora consiste na ligação necessária entre generalidade e singularidade na autoconsciência, e não na "ligação infeliz entre uma primeira evidência no saber e o programa de um sistema a partir de um único princípio" ${ }^{23}$, embora tal ligação não seja entendida e aprofundada explicitamente por Fichte como conteúdo do seu insight. A autoconsciência destacarse-ia pelo fato de que um singular é caracterizado por uma atividade que apresenta generalidade estrita. A forma de pensamentos que envolvem 'eu' (Ich-Gedanken) seria por si geral, no entanto, ao mesmo tempo essa forma estaria ligada ao exercício singular e concreto da autoconsciência.

\section{b) A diferença entre a intenção do artigo e a intenção de Fichte}

Segundo Henrich, a diferença entre o artigo sobre Fichte e a intenção de Fichte resulta do caráter abstrato da concepção fichtiana do sistema: isso ficaria claro particularmente com relação à interpretação da terceira fórmula, na medida em que aqui a tensão entre o problema da autoconsciência e a construção de um sistema monista ficaria manifesta. Segundo Henrich, com a terceira fórmula a estrutura da Doutrina da Ciência claramente teria mudado. $O$ que está em primeiro plano não é mais a evidência do 'eu', mas a fundamentação do sistema, o que faz com que os sujeitos singulares e finitos sejam entendidos como manifestações de Deus. Henrich menciona aqui os seguintes pontos: 1) no artigo levanta-se o problema de um quadro para a ligação dos sujeitos singulares dentro de uma forma fundamental e invariante. 
Consequentemente, deve-se supor um fundamento para a unidade da autorreferência, no entanto, este não pode ser entendido, como em Fichte, como um princípio real e metafísico, mas meramente como fundamento da possibilidade em sentido kantiano; 2) Fichte não queria delegar o esclarecimento da unidade da relação consigo mesmo a uma instância transcendente, mas o princípio do 'Uno' deveria tornar compreensível a gênese interna da relação consigo mesmo de sujeitos; 3) enquanto Fichte atribui ao sujeito singular uma autoconsciência imediata pela qual pode possuir um saber do seu estar-envolvido (Einbezogensein) no absoluto, o artigo não partiria do pressuposto de um sistema monista, não podendo, como isso, basear-se no saber de um absoluto; 4) o artigo não alegaria, como Fichte, uma fundamentação última em forma sistemática. Diferentemente de Fichte, ele também não defenderia nenhum princípio absoluto do qual os sujeitos finitos fazem parte, mas entenderia o 'eu penso' a partir de Kant como condição de um pensamento finito; 5) com isso, no artigo o modo kantiano de abordar a autoconsciência seria uma das linhas norteadoras, segundo a qual o 'eu penso' deve ser entendido como ato inteligente no qual o diverso do mundo está contido. Diferentemente de Fichte, do pertencimento do sujeito ao 'Uno' não se segue a sua auto-abdicação, mas sua auto-efetuação. ${ }^{24}$ Finalmente, Henrich ressalta um aspecto profundo que o artigo e a concepção de Fichte têm em comum: como Fichte, o artigo não queria apenas resolver problemas teóricos, mas possibilitar um entendimento da vida. Disto resultaria também a importância da terceira fórmula. Enquanto no artigo Henrich aparentemente se orienta pela terceira fórmula, porque nela o problema do círculo seria resolvido pela pressuposição de um fundamento transcendente, agora ele critica, com relação à Doutrina da Ciência tardia de Fichte, que "a relação consigo mesmo da forma do eu é explicada de tal forma que ela precisa ser pressuposta várias vezes ao longo da explicação, ou que em vez desse círculo ocorre uma duplicação da identidade dos sujeitos singulares". ${ }^{25}$ Além disso, Fichte não conseguiria estabelecer uma ligação coerente entre a auto-abdicação dos sujeitos e a sua auto-efetuação. Assim, a concepção da auto-abdicação, segundo a qual os sujeitos singulares realizam uma ordem superior, torna-se um modelo da auto-aniquilação, porque Fichte não poderia explicar adequadamente a autorreferência do sujeito. A dedução da autoconsciência singular a partir do saber desse modo não poderia ser bem sucedida, porque segundo Henrich a subjetividade possuiria um primado com relação ao saber, na medida em que não haveria nenhum saber sem que esse seja considerado verdadeiro, sendo, com isso, conteúdo da 'crença' de um sujeito. ${ }^{26}$ Pelo fato de que a forma do eu não poderia ser explicada a partir de um princípio único do sistema, confirma-se para Henrich a importância fundamental da autoconsciência no insight de Fichte.

\section{3) Sobre a conexão entre as duas perspectivas}

Enquanto em "O insight originário de Fichte" Henrich põe em foco a questão da condição estrutural do eu e a explicação fichtiana dessa condição pela estrutura interna de intuição e conceito, seu livro atual trata da questão da dimensão intersubjetiva da autoconsciência singular. Na medida em que a relação entre generalidade e singularidade torna-se central para Henrich, fica mais importante a segunda fórmula que caracteriza o eu como pôr a si mesmo como pondo a si mesmo:

É precisamente um sujeito só que se entende como 'eu' - e justamente aquele que é o pensador de um pensamento. No entanto, aquilo que [determina] como ele se entende coincide na sua condição completamente com aquilo que todos que são 
capazes de pensar pensamentos que envolvem 'eu' também co-entendem em cada um desses seus pensamentos. ${ }^{27}$ começar a dirigir a atenção da filosofia para o fato de que tal sujeito sempre deve dispor de um conceito de si mesmo e que o utiliza em toda caracterização proposicional de si mesmo." ${ }^{28}$ Nisto, o auto-entendimento do sujeito como sujeito seria uma condição da relação fundamental do sujeito com conceitos, com seu uso em atribuições e, com isso, da racionalidade. Segundo Henrich, o artigo sobre Fichte ressaltaria dois conteúdos do insight de Fichte: primeiro, a autorreferencialidade de casos particulares da autoconsciência efetivamente exercida. Segundo, a tese de que uma análise dessa autorreferencialidade segundo modelos comuns não seria possível. Enquanto no artigo sobre Fichte Henrich busca evitar a circularidade da autoconsciência ao supor um fundamento não-reflexivo que estaria anteposto à autoconsciência, agora ele entende o caráter paradoxal da autorreferência enquanto pressuposto mútuo como evidência fundamental que apontaria para um limite no auto-esclarecimento do espírito. ${ }^{29}$ Enquanto no artigo sobre Fichte Henrich critica Kant como representante proeminente da teoria da reflexão, no livro atual seu ponto de partida explicitamente é a concepção kantiana do pensamento finito. Segundo Henrich, há um terreno comum da sua posição e da primeira versão da Doutrina da Ciência, na medida em que o conteúdo do insight de Fichte é um fato originário. No entanto, Fichte mudaria essa posição com a nova orientação pelo princípio do saber da Doutrina da Ciência tardia..$^{30}$ Segundo Henrich, a diferença entre a posição de Fichte e a sua posição resultaria do lugar atribuído à autoconsciência singular: enquanto Fichte, no quadro do seu programa sistemático, entenderia a autorreferência do sujeito singular a partir do eu absoluto, Henrich defende a tese de que "uma autoconsciência como relação consigo mesmo que pode articular-se através do pronome 'eu' só pode ser atribuída a um sujeito singular". ${ }^{31}$ Segundo Henrich, a autoconsciência singular não pode ser explicada por uma pressuposta forma universal, como em Fichte, mas ao contrário deve ser entendida como "lugar do enraizamento da forma da validade universal" ${ }^{32}$, porque não haveria nenhuma esfera de validade e verdade que esteja separada da subjetividade. Henrich enfatiza nisto a conexão das correlações, centrais para a autoconsciência, entre singularidade e generalidade e entre intuição (exercício) e conceito (saber de si): "o saber de si que se refere ao sujeito singular que sou só pode ocorrer se se atribui à forma desse saber de um sujeito a generalidade que está correlacionada com uma racionalidade elementar e espontânea" ${ }^{33}$ No entanto, pelo motivo de que a correlação entre intuição e conceito, central em Fichte, não traz "nenhum esclarecimento acerca do modo específico de como o autoconhecimento e o ser-para-si de um sujeito singular em geral é realizado" ${ }^{34}$, em Fichte o exercício da autoconsciência não estaria ligado ao saber de si de sujeitos singulares.

17 Finalmente, voltamo-nos para a relação entre as duas perspectivas em Fichte. A teoria fichtiana da autoconsciência tem como ponto de partida duas questões que ficam abertas em Kant: primeiro, a relação entre intuição e conceito, e segundo, o problema da intersubjetividade. Kant, na filosofia transcendental, concebe intuição e conceito como componentes complementares do conhecimento, cuja unidade é fornecida pela unidade da apercepção. Nisto, a apercepção nem pode ser caracterizada como intuição, nem como conceito. No entanto, na medida em que Kant a identifica com o próprio entendimento, ela pode ser associada com o conceito. Em contraste, a questão de uma concepção da intersubjetividade levanta-se na filosofia prática de Kant, a saber, com 
relação ao imperativo categórico "Aja só conforme aquela máxima pela qual você pode ao mesmo tempo querer que ela seja uma lei universal" (AA IV, 421). Na Doutrina da Ciência nova methodo (1796-1799), na qual Fichte parte diretamente da filosofia transcendental de Kant, ele tenta responder as duas perguntas: por um lado, através de uma fundamentação da relação entre intuição e conceito na autoconsciência ele busca resolver a questão da raiz comum e desconhecida dos troncos do conhecimento que correspondem a estes, isto é, da sensibilidade e do entendimento. Enquanto Kant na sua concepção do imperativo categórico meramente pressupõe outros sujeitos, por outro lado, no $\S 13$ da Doutrina da Ciência nova methodo, Fichte empreende a tentativa de uma dedução do sujeito individual e finito a partir da vontade pura como forma geral da subjetividade. Henrich enfatiza a importância da teoria fichtiana da intersubjetividade ${ }^{35}$, no entanto, pelo motivo de que é a Doutrina da Ciência tardia de Fichte o que está em foco na sua análise, ele não discute nesse contexto especificadamente a Doutrina da Ciência nova methodo, na qual Fichte, como o primeiro na história da filosofia, concebe uma teoria da intersubjetividade. Para Fichte, o criticismo de Kant, comparado à Doutrina da Ciência, é bastante inacabado e por isso não é um sistema, porque Kant não teria desenvolvido uma teoria da intersubjetividade. ${ }^{36}$ Para caracterizar seu princípio fundamental, Fichte agora não utiliza mais o termo "eu absoluto", porque este teria provocado o mal entendimento de um princípio metafísico. Em vez disso, ele caracteriza o princípio fundamental como "razão finita em geral" (WLnm-H, GA IV/2, 27, WLnm-K, GA IV/3, 341) e na Segunda Introdução à Doutrina da Ciência (1797), escrita no mesmo período, ele identifica sua concepção da intuição intelectual com o princípio kantiano da apercepção pura. Kant descreve o eu como „uma representação vazia de conteúdo“ (B 404). Como para Kant um conhecimento do eu que seja independente da experiência não é possível, ele critica a possibilidade de uma intuição intelectual como produção de uma coisa por um entendimento divino ou intuição da coisa em si. Fichte empreende agora a tentativa de uma superação da concepção dualista de Kant através da reabilitação da intuição intelectual. Segundo Fichte, Kant desse modo não podia mostrar como uma consciência imediata do imperativo categórico é possível (cf. ZE, GA I/4, 225). Enquanto em Kant a intuição é somente receptiva, motivo este pelo qual ele entende o eu como forma meramente lógica, Fichte concebe o eu enquanto unidade de forma e conteúdo como „princípio da subjetividade em geral“". ${ }^{37}$ Fichte explicita a estrutura interna do eu através da relação entre intuição e conceito. Ele entende o conceito como produto da intuição enquanto atividade voltada para si mesma, ato este no qual ela representa a si mesma, ou seja, se põe como pondo a si mesma. Nisto, Fichte caracteriza a intuição como atividade prático-real e o conceito como atividade teórico-ideal, cuja pressuposição mútua ele concebe como círculo da consciência, que ele funda no princípio da vontade pura como unidade de liberdade e limitação. Nesse contexto, Fichte aponta para a dificuldade de uma concepção que supõe apenas uma vontade empírica: tal concepção é necessariamente circular por pressupor o conhecimento do objeto ao qual o querer se refere. Para resolver o círculo, Fichte introduz a vontade pura: „foi postulado um querer que não pressuponha o conhecimento do objeto, mas que já o envolva“ (WLnm-K, GA IV/3, 439). Nisto, partindo de Kant, Fichte caracteriza a vontade pura como imperativo categórico, apontando ao mesmo tempo uma diferença no significado desse termo: enquanto em Kant o imperativo categórico deve explicar apenas a consciência do dever, ficando, como isso, relacionado com a dimensão moral, aqui a vontade pura seria empregada para dar a "explicação da consciência em geral“ 
(WLnm-K, GA IV/3, 440). Nesse contexto, Fichte critica a determinação insuficiente do conceito de númeno em Kant, responsabilizando-a por um dualismo do mundo sensível e supra-sensível. É verdade que Kant entende a liberdade da vontade como númeno que é dado como fato de razão no sujeito pela lei moral. No entanto, ela é determinante apenas em sentido prático, sem ser cognoscível teoricamente. Enquanto em Kant o númeno como puro ente do entendimento é um conceito limite que possui apenas um significado negativo, Fichte dá para esse conceito um sentido positivo, ao tornar a vontade pura o fundamento explicativo teórico-prático da consciência, que seria „ao mesmo tempo objeto do conhecimento e causalidade“ (WLnm-K, GA IV/3, 447). Segundo Fichte, o erro fundamental de Kant consiste no fato de ele supor apenas uma intuição sensível e nenhuma intuição intelectual, o que deixaria a estrutura fundamental da subjetividade não refletida.

Henrich critica que o modelo monista de sistema defendido por Fichte, com sua concepção do eu absoluto, tem por consequência que se negliencie o exercício atual de pensamentos sobre si mesmo (Ich-Gedanken) e sua evidência na autoconsciência concreta. ${ }^{38}$ No entanto, na Doutrina da Ciência nova methodo Fichte reage à crítica do "transcendentismo“39 do eu absoluto no Fundamento de 1794/95, concebendo uma nova teoria da subjetividade concreta (GWL, GA I/2, 414). Agora Fichte começa com um postulado de reflexão como instrução de um agir dirigido à autoconsciência concreta, da qual ele extrai a forma geral da autoconsciência. Em seguida, ele concretiza o conceito de eu pela dedução das condições dessa estrutura abstrata da consciência, derivando dela o individuo. Nisto, no conceito de eu está presente desde o início a dimensão da intersubjetividade, na medida em que este surge pela exortação (Aufforderung). Como autoconsciência possível, o eu tem que determinar a si mesmo. No entanto, ele é uma autoconsciência atual como indivíduo apenas através do outro, que o determina ao exortá-lo à liberdade, i.e., à autodeterminação. Para Henrich, a oposição entre autodeterminação e ser-determinado, que seria uma experiência fundamental da modernidade, mostra-se proeminentemente no desdobramento do caminho do pensamento de Fichte: este começa com a exortação à autodeterminação, no sentido da revolução francesa, mas em seguida realiza uma virada, depois da qual Fichte entende a autodeterminação do sujeito como manifestação do uno Deus vivo, no entanto, sem suspender a doutrina da liberdade. Henrich enxerga nisto o motivo fundamental também do seu próprio filosofar: „Na minha própria motivação, essa ampliação e esse aprofundamento da tentativa fichtiana de um entendimento fundamental da vida consciente e do caráter particular da sua liberdade moveu-me para a filosofia“..40 Partindo da nova fundamentação da ética pela liberdade do ser racional finito na qual, no entanto, o fundamento da finitude da liberdade permanece não refletido, Fichte na sua doutrina tardia busca explicar a ligação entre finitude e liberdade autônoma, o que se exprime particularmente na concepção do „estar inserido“. Essa limitação interna da liberdade não significa a determinação por fins dados ou a dependência de autoridades, mas o próprio saber do sujeito autoconsciente da sua manifestação no agir como autodeterminação autônoma. ${ }^{41}$ No entanto, uma diferença fundamental entre a concepção fichtiana e a posição de Henrich consiste no fato de que Fichte deriva o sujeito finito da forma universal da subjetividade, enquanto segundo Henrich a forma universal precisa ser localizada no sujeito singular, no entanto, sem que a autoconsciência concreta possa ser deduzida a partir desta. Além disso, Henrich critica a concepção fichtiana de um sistema monista a partir de um princípio, alegando uma oposição entre o pensamento finito e sua fundamentação, que resultaria, por um lado, 
do limite da explicabilidade da autoconsciência e, por outro lado, do fato de que a dimensão que funda a finitude é inescrutável. ${ }^{42}$ Segundo Henrich, a contribuição de Fichte consiste em ir além de Kant ao perguntar qual a estrutura da autoconsciência:

Kant enxergou no exercício do ,Eu penso ' um ato inteligente que imediatamente visa a uma unidade conceitual, que aponta seu sujeito singular na sua espontaneidade discursiva, mas que também insere esse sujeito no múltiplo de um mundo [...] Pela descoberta de Fichte tinha ficado claro que a autoconsciência na qual o sujeito abrange a si mesmo como tal não pode ser entendida através de um modelo facilmente compreensível. Isso sugere que as condições da sua constituição devem ser contempladas na reflexão sobre sua estrutura - e isso ainda mais porque a fundamentação da filosofia prática de Kant já torna necessária tal perspectiva. ${ }^{43}$

Nesse aspecto, com relação à elucidação da relação entre a singularidade e a universalidade da autoconsciência, a orientação por Kant que é focalizada por Henrich pode receber uma continuação frutífera pela teoria da intersubjetividade que é concebida por Fichte na Doutrina da Ciência nova methodo.

\section{Referências bibliográficas}

DÜRR, S. (2018) Das „Princip der Subjektivität überhaupt“. Fichtes Theorie des Selbstbewusstseins (1794-1799), in: JAMME, CH. \& VIEWEG, к. (eds.) Jena-sophia. Studien und Editionen zum deutschen Idealismus und zur Frühromantik. Abteilung II - Studien 16. Paderborn: Wilhelm Fink

FICHTE, J. G. (1962-2012) Gesamtausgabe der Bayerischen Akademie der Wissenschaften, ed. Reinhard Lauth et al. Stuttgart-Bad Cannstatt: Frommann-Holzboog.

FICHTE, J. G. (1984) A Doutrina-Da-Ciência de 1794 e outros Escritos, tradução de Rubens Rodrigues Torres Filho, São Paulo: Abril Cultural.

HENRICH, D. (1966) "Fichtes ursprüngliche Einsicht." In: Henrich, D., Wagner, H. (eds) Subjektivität und Metaphysik. Festschrift für Wolfgang Cramer. Frankfurt am Main: Klostermann

HENRICH, D. (1967) Fichtes ursprüngliche Einsicht. Frankfurt am Main: Klostermann.

HENRICH, D. (1970) „Selbstbewusstsein. Kritische Einleitung in eine Theorie“, in: BUBNER, R., CRAMER, K., WIEHL, R. (eds.) Hermeneutik und Dialektik. Aufsätze I, Methode und Wissenschaft, Lebenswelt und Geschichte. Tübingen: J.C.B. Mohr (Paul Siebeck), pp. 257-284 HENRICH, D. (2007) „Selbstsein und Bewusstsein“, in: e-Journal Philosophie der Psychologie 8: http://www.jp.philo.at/texte/HenrichD1.pdf, pp.1-19 HENRICH, D. (2019) Dies Ich, das viel besagt. Fichtes Einsicht nachdenken. Frankfurt am Main: Klostermann METZ, w. (2003) „Die produktive Reflexion als Prinzip des wirklichen Bewusstseins“, In: FICHTE-STUDIEN 20, pp. 69-99. 


\section{NOTAS}

1. HENRICH, Einsicht, p. 191.

2. HENRICH, Einsicht, p. 192.

3. Cf. HENRICH, Einsicht, p. 196.

4. HENRICH, D. Einsicht, p. 199.

5. Ibidem.

6. HENRICH, D. Einsicht, p. 201.

7. Ibidem.

8. HENRICH, D. Einsicht, p. 212.

9. HENRICH, D. Einsicht, p. 214.

10. HENRICH, D. (1970) „Selbstbewusstsein. Kritische Einleitung in eine Theorie“, in: BUBNER, R., CRAMER, K., WIEHL, R. (eds.) Hermeneutik und Dialektik. Aufsätze I, Methode und Wissenschaft, Lebenswelt und Geschichte. Tübingen: J.C.B. Mohr (Paul Siebeck), pp. 257-284 (doravante: Selbstbewusstsein), aqui: p. 275.

11. Cf. HENRICH, D. „Selbstbewusstsein“, p. 280.

12. Cf. HENRICH, D. (2007) „Selbstsein und Bewusstsein“, in: e-Journal Philosophie der Psychologie 8: http://www.jp.philo.at/texte/HenrichD1.pdf, pp.1-19, aqui: p. 1. (doravante: „Selbstsein und Bewusstsein“).

13. Cf.. HENRICH, D. „Selbstsein und Bewusstsein“, pp. 1-2.

14. HENRICH, D. „Selbstbewusstsein“, p. 265.

15. A respeito das observações que seguem, cf. DÜRR, S. (2018) Das „Princip der Subjektivität überhaupt“. Fichtes Theorie des Selbstbewusstseins (1794-1799), in: JAMME, CH. \& VIEWEG, K. (eds.) jenasophia. Studien und Editionen zum deutschen Idealismus und zur Frühromantik. Abteilung II - Studien 16. Paderborn: Wilhelm Fink, pp. 196-213; 295-299.

16. Aqui e doravante, $\mathrm{DC}$, seguido pelo número de página, refere-se a Fichte, J. G. A Doutrina-Da-Ciência de 1794 e outros Escritos , tradução de Rubens Rodrigues Torres Filho, São Paulo: Abril Cultural 1984.

17. Assim, no manuscrito de Halle da Doutrina da Ciência nova methodo Fichte diz: „Dessa consciência da nossa consciência ficamos conscientes [...] somente ao torná-la novamente um objeto [...] e assim ao infinito [...] Tal sofismar subjazia a todos os sistemas até hoje, até ao kantiano." (WLnm-H, GA IV/2, 30)

18. A respeito do modelo de Fichte no Fundamento de 1795/95, cf. também METZ, w. (2003) „Die produktive Reflexion als Prinzip des wirklichen Bewusstseins“, in: FICHTE-STUDIEN 20, pp. 69-99.

19. HENRICH, D. Dies Ich, Im Vorblick, X.

20. HENRICH, D. Dies Ich, p.86.

21. Vgl. HENRICH, D. Dies Ich, pp. 87-88.

22. HENRICH, D. Dies Ich, pp. 96-97.

23. HENRICH, D. Dies Ich, p. 97.

24. Vgl. HENRICH, D. Dies Ich, pp. 185-195.

25. HENRICH, D. Dies Ich, pp. 182-183.

26. Vgl. HENRICH, D. Dies Ich, p. 231.

27. HENRICH, D. Dies Ich, p. 98.

28. HENRICH, D. Dies Ich, p. 256.

29. Vgl. HENRICH, D. Dies Ich, p. 269.

30. Vgl. HENRICH, D. Dies Ich, p. 254.

31. HENRICH, D. Dies Ich, p. 255. 
32. Vgl. HENRICH, D. Dies Ich, p. 256.

33. HENRICH, D. Dies Ich, p. 245.

34. HENRICH, D. Dies Ich, p. 248.

35. Vgl. HENRICH, D. Dies Ich, p. 194-195.

36.

Isso mostra-se em dois pontos: por um lado, Kant aplica o princípio do juízo reflexionante somente ao julgamento da conformidade a fins de produtos orgânicos da natureza, mas não à construção de conceitos de fins e da sua efetuação em ações através de sujeitos autoconscientes.

Por outro lado, Kant entende o princípio da suposição de seres racionais, isto é, o imperativo categórico, apenas como princípio prático, não como fundamento do conhecimento. Desse modo,

ele pressupõe a existência de outros seres racionais, em vez de deduzi-la sistematicamente.

37. Fichte a Reinhold, carta do dia 28 de abril de 1795, GA III/2, 314-315.

38. Cf. HENRICH, D. Dies Ich, p. 116.

39. Tal objeção encontra-se em Friedrich Hölderlin, Friedrich Immanuel Niethammer e Carl Chr.

E. Schmid.

40. HENRICH, D. Dies Ich, p.81.

41. Cf. HENRICH, D. Dies Ich, p. 83.

42. Cf. HENRICH, D. Dies Ich, pp. 276-277.

43. HENRICH, D. Dies Ich, pp. 193-194.

\section{RESUMOS}

The first part of the paper deals with the interpretation of Fichte defended by Henrich in the article "Fichte's Original Insight" (1966). Here Henrich's theses on the circularity and reflexivity of self-consciousness in relation to the Fichtian model of self-consciousness are in focus. The second part of the paper discusses Henrich's reflection on the 1966 article in his current book Dies Ich, das viel besagt (2019). Here, Henrich no longer puts the critique of the theory of selfconsciousness as reflection in the focus of his analyses of self-consciousness, but the relation between generality and singularity. In the third part, the question is raised about the relation between the two perspectives.

\section{ÍNDICE}

Keywords: Dieter Henrich, Fichte, Self-consciousness, Generality, Singularity

\section{AUTOR}

SUZANNE DÜRR

Ludwig-Maximilians-Universität München 